Check for updates

Cite this: RSC Adv., 2017, 7, 22699

Received 23rd February 2017

Accepted 17th April 2017

DOI: $10.1039 / c 7 r a 02237 a$

rsc.li/rsc-advances

\title{
Design and synthesis of uracil urea derivatives as potent and selective fatty acid amide hydrolase inhibitors $\uparrow$
}

\author{
Yan Qiu, + $^{\mathrm{a}}$ Jie Ren, $\$^{\mathrm{a}}$ Hongwei Ke, ${ }^{\mathrm{bc}}$ Yang Zhang, ${ }^{\mathrm{a}}$ Qi Gao, ${ }^{a}$ Longhe Yang, ${ }^{\mathrm{d}}$ \\ Canzhong $\mathrm{Lu} \mathrm{DD}^{\mathrm{b}}$ and Yuhang $\mathrm{Li}$ (iD *ab
}

\begin{abstract}
Fatty acid amide hydrolase (FAAH) is one of the key enzymes involved in the biological degradation of endocannabinoids, especially anandamide. Pharmacological blockage of FAAH restores the levels of endocannabinoids, providing therapeutic benefits in the management of inflammation, depression and multiple sclerosis. In this study, a series of uracil urea derivatives as FAAH inhibitors were designed and synthesized. Structural modifications at the C5 position and side chain of $\mathrm{N}$-hexyl-2,4-dioxo-3,4dihydropyrimidine-1(2H)-carboxamide (1a) led to FAAH inhibitors with improved potency and selectivity. Structure-activity relationship (SAR) studies indicated that C5 electron-withdrawing substituents were preferred for optimal potency but not for selectivity, whereas replacement of the alkyl chain with phenylalkyl moieties or biphenyl groups significantly improved both inhibitory potency and selectivity towards FAAH. Two highly potent picomolar FAAH inhibitors (4c, IC $50=0.3 \pm 0.05 \mathrm{nM} ; 4 \mathrm{~d}, \mathrm{IC}_{50}=0.8 \pm$ $0.1 \mathrm{nM}$ ) were developed. Compound $4 \mathrm{c}$ inhibited FAAH in a rapid, selective, noncompetitive, and irreversible pattern. This study provides several highly potent and selective FAAH inhibitors and an optimized chemical scaffold for the development of FAAH inhibitors. We anticipate that these FAAH inhibitors will enable new possibilities in understanding FAAH functions and development of therapeutics for pain and inflammatory diseases.
\end{abstract}

\section{Introduction}

Fatty acid amide hydrolase (FAAH) is a member of the amidase signature family, responsible for the inactivation of endogenous cannabinoids, especially anandamide (AEA).${ }^{1-3}$ AEA modulates a wide range of physiological processes through the interaction with $\mathrm{G}$ protein-coupled $\mathrm{CB} 1$ and $\mathrm{CB} 2$ cannabinoid receptors. Genetic and pharmacological blocking of FAAH leads to increased endogenous AEA levels without the undesirable "cannabinoid effects" caused by cannabinoid receptor agonists. $^{4-6}$ Therefore, restoring the endogenous AEA by FAAH inhibition has become an alternative therapeutic strategy for inflammation, cancer, and neuropathic diseases..$^{5,7-11}$

${ }^{a}$ Medical College, Xiamen University, Xiamen, Fujian 361102, P. R. China. E-mail: yuhangli@fjirsm.ac.cn

${ }^{b} X i a m e n$ Institute of Rare-earth Materials, Haixi Institutes, Chinese Academy of Sciences, Fujian 361024, P. R. China

${ }^{c}$ College of Ocean and Earth Science, Xiamen University, Xiamen, Fujian, 361005, P. R. China

${ }^{d}$ Engineering Research Centre of Marine Biological Resource Comprehensive Utilization, Third Institute of Oceanography, State Oceanic Administration, Xiamen 361102, P. R. China

$\dagger$ Electronic supplementary information (ESI) available. See DOI: 10.1039/c7ra02237a

\$ Equal contribution.
So far, there are two main categories of FAAH inhibitors that have been developed. ${ }^{12-14}$ First, reversible inhibitors, such as the $\alpha$-ketoheterocycle-based inhibitors, bind to the active serine residue of FAAH with a reversible hemiketal bond. OL-135 is the most well-studied potent and reversible FAAH inhibitor., ${ }^{\mathbf{4}, 15}$ Second, irreversible inhibitors, including aryl carbamates, ${ }^{17-20}$ ureas $^{21-25}$ and sulfonyl fluoride analogues, ${ }^{26}$ which form covalent binding with the catalytic site of FAAH, e.g., URB597. ${ }^{27}$ Administration of URB597 to rats elevated endogenous AEA levels and exhibited anxiolytic effects in animal models., ${ }^{5,28}$ Additionally, benzothiazole, ${ }^{29} \quad \beta$-lactam, ${ }^{30}$ (thio)hydantoins ${ }^{31}$ and some nonsteroidal anti-inflammatory drugs (NSAIDs) (22-34 $^{34}$ also have been reported to inhibit FAAH.

Although the overall physiological role of FAAH has been reported, it is difficult to distinguish the function of FAAH in each specific tissue and organ. The reason is the wide distribution of FAAH in the whole body and lack of suitable topical FAAH inhibitors. Most of current FAAH inhibitors have low blood clearance and readily distributed and inhibit FAAH throughout the body after treatment. They are suitable for the systemic inhibition of FAAH, but it's difficult to obtain targeted FAAH inhibition in the specific tissues without inhibiting FAAH in other non-targeted sites. Given the critical pharmacological properties of FAAH, understanding the function of FAAH in different tissues is of great significance. FAAH inhibitors 

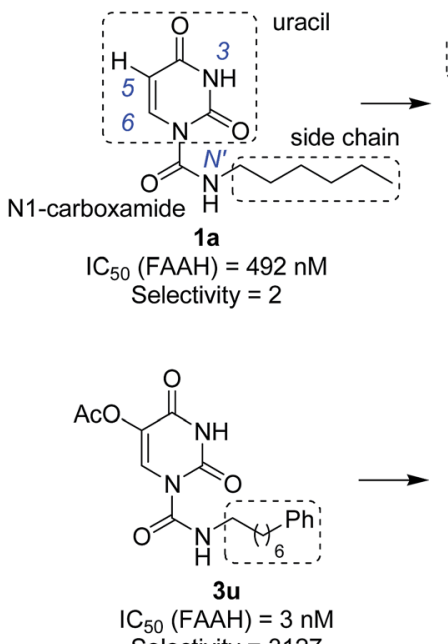

Selectivity $=3127$

Fig. 1 The design strategies of uracil urea derivatives as highly potent and selective FAAH inhibitors. The selectivity represents the selectivity of uracil urea derivatives towards FAAH over NAAA.

suitable for the topical administration is highly desired to explore functions of FAAH in different tissues and organs.

In our previous study, ${ }^{35}$ we found that uracil urea 1a (Fig. 1), an acid ceramidase (AC) inhibitor $\left(\mathrm{IC}_{50}=426 \pm 104 \mathrm{nM}\right),{ }^{36}$ was also a potent FAAH $\left(\mathrm{IC}_{50}=492 \pm 53 \mathrm{nM}\right)$ and $N$ acylethanolamine-hydrolysing acid amidase (NAAA) inhibitor $\left(\mathrm{IC}_{50}=990 \pm 170 \mathrm{nM}\right)$. To develop FAAH inhibitors with properties suitable for topical FAAH inhibition and improve the selectivity of 1a towards FAAH, we modified the uracil electronic properties and the side chain conformation of 1a. A series of uracil urea derivatives designed as selective FAAH inhibitors were synthesized and characterized. The results showed that modification of 1a targeting the uracil ring improved the inhibition potency towards FAAH, and the side chain replacement with phenylalkyl moieties or biphenyl groups enhanced both potency and selectivity (Fig. 1). Several highly potent and selective FAAH inhibitors were reported, including two picomolar inhibitor, $4 \mathbf{c}\left(\mathrm{IC}_{50}=0.3 \pm 0.05 \mathrm{nM}\right)$ and $4 \mathbf{d}\left(\mathrm{IC}_{50}=0.8 \pm\right.$ $0.1 \mathrm{nM})$, a series of nanomolar inhibitors, e.g., $\mathbf{3 f}\left(\mathrm{IC}_{50}=4 \pm 0.9\right.$ $\mathrm{nM}), 3 \mathbf{u}\left(\mathrm{IC}_{50}=3 \pm 0.4 \mathrm{nM}\right), \mathbf{4 a}\left(\mathrm{IC}_{50}=1.1 \pm 0.2 \mathrm{nM}\right)$ and $4 \mathbf{b}$ $\left(\mathrm{IC}_{50}=8.3 \pm 1.2 \mathrm{nM}\right)$.

\section{Chemistry}

The uracil ureas 1a, 1c, 1d, 2a, 2d, 2i-2k, 3a-3u, 4a-4d were prepared by the reaction of isocyanates with 5 -substituted uracils following a reported procedures with minor modification. ${ }^{36}$ Isocyanates were synthesized via Curtius rearrangement of appropriate acylazides prepared from successive reactions of the corresponding acid with oxalyl chloride $\left((\mathrm{COCl})_{2}\right)$ and sodium azide $\left(\mathrm{NaN}_{3}\right)$ (Scheme 1$){ }^{20} \mathbf{1 b}$ and $\mathbf{1 e}$ were synthesized following a literature procedure. ${ }^{36} \mathbf{1 b}$ was prepared by the reaction of hexyl isocyanate with 3-methyl substituted uracil 1 $\mathbf{1 b}$ 1. 1b-1 was obtained by reaction of $N$-Boc uracil and iodomethane (MeI), and then deprotection with $\mathrm{HCl}$ in $\mathrm{MeOH}$

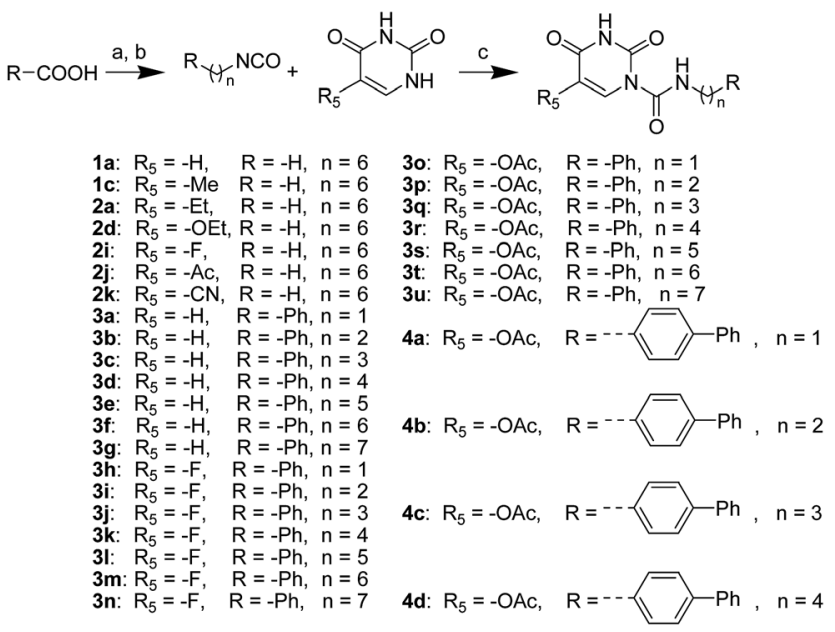

Scheme 1 The synthesis of compounds $1 a, 1 c, 2 a, 2 d, 2 i-2 k, 3 a-3 u$, 4b-4d. Reagents and conditions: (a) $(\mathrm{COCl})_{2}$, cat. DMF, $\mathrm{CH}_{2} \mathrm{Cl}_{2}$, then $\mathrm{NaN}_{3}$ in $\mathrm{H}_{2} \mathrm{O}, 0^{\circ} \mathrm{C}$; (b) toluene, reflux; (c) DMAP, pyridine, $60^{\circ} \mathrm{C}$.

(Scheme 2). 1e was synthesized by reaction of uracil with triphosgene followed by treatment with $N$-methylhexanamine (Scheme 3). $\mathbf{2 b}$ and $\mathbf{2 c}$ were prepared with 3 -step procedure starting from $\mathbf{2 b}-\mathbf{1}$ and $2 \mathrm{c}-\mathbf{1}$. Compound $2 \mathbf{b}-\mathbf{1}$ and $2 \mathrm{c}-\mathbf{1}$ were protected by $t$-butyl di-methylsilyl chloride (TBSCl) and directly used in the carbamoylation reaction, followed by deprotection

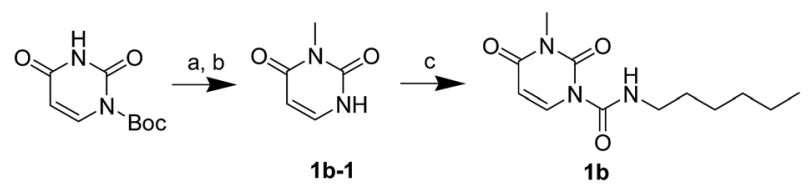

Scheme 2 The synthesis of compound $1 \mathrm{~b}$. Reagents and conditions: (a) $\mathrm{Mel}, \mathrm{Cs}_{2} \mathrm{CO}_{3}, \mathrm{THF}$, room temperature; (b) $\mathrm{HCl}, \mathrm{CH}_{3} \mathrm{OH}$, room temperature; (c) hexyl isocyanate, DMAP, pyridine, $60{ }^{\circ} \mathrm{C}$.

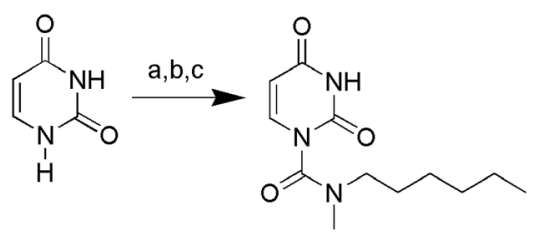

Scheme 3 The synthesis of compound 1e. Reagents and conditions: (a) $\mathrm{NaH}$, triphosgene, $\mathrm{THF}$, room temperature; (b) $\mathrm{HCl}, \mathrm{CH}_{3} \mathrm{OH}$, room temperature; (c) DMAP, pyridine, N-methylhexylamine, room temperature.

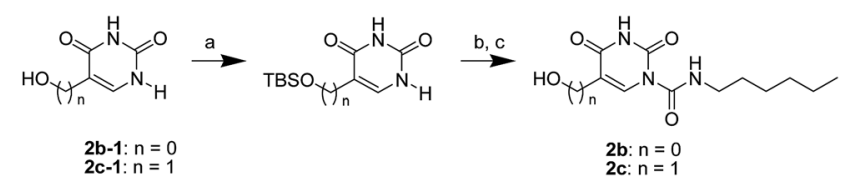

Scheme 4 The synthesis of compounds $2 \mathrm{~b}$ and $2 \mathrm{c}$. Reagents and conditions: (a) pyridine, TBSCl, room temperature; (b) hexyl isocyanate, DMAP, pyridine, $60^{\circ} \mathrm{C}$; (c) TBAF, THF, room temperature. 


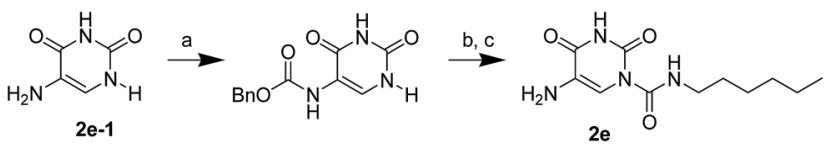

Scheme 5 The synthesis of compound 2e. Reagents and conditions: (a) pyridine, $\mathrm{CbzCl}$, room temperature; (b) hexyl isocyanate, DMAP, pyridine, $60^{\circ} \mathrm{C}$; (c) TMSI, THF, room temperature.
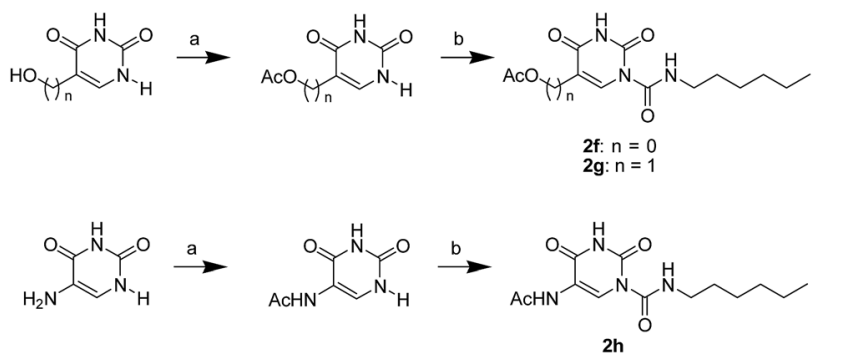

Scheme 6 The synthesis of compounds $2 \mathrm{f}, 2 \mathrm{~g}$ and $2 \mathrm{~h}$. Reagents and conditions: (a) pyridine, $\mathrm{Ac}_{2} \mathrm{O}$, room temperature; (b) hexyl isocyanate, DMAP, pyridine, $60^{\circ} \mathrm{C}$.

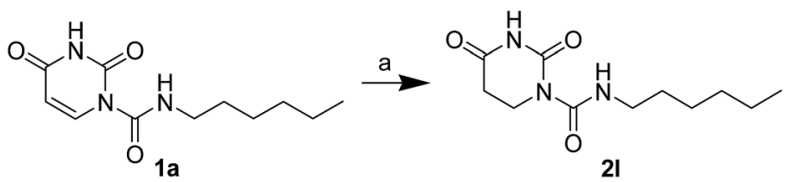

Scheme 7 The synthesis of compound 2l. Reagents and conditions: (a) $10 \% \mathrm{Pd} / \mathrm{C}, \mathrm{H}_{2}, \mathrm{CH}_{3} \mathrm{OH}$, room temperature.

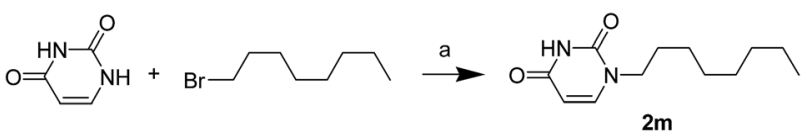

Scheme 8 The synthesis of compound $2 \mathrm{~m}$. Reagents and conditions: (a) $\mathrm{K}_{2} \mathrm{CO}_{3}, \mathrm{DMF}$, room temperature.

with tetrabutylammonium fluoride (TBAF) (Scheme 4). 5-Amino uracil (2e-1) protected with benzyl carbonochloridate $(\mathrm{CbzCl})$ in pyridine was directly used in the carbamoylation reaction, and followed by deprotection with trimethylsilyl iodide (TMSI) to afford $2 \mathbf{e}$ (Scheme 5). $\mathbf{2 f - 2 h}$ were synthesized by treatment of the uracil derivatives with acetic anhydride $\left(\mathrm{Ac}_{2} \mathrm{O}\right)$ followed by reaction with isocyanates (Scheme 6). $2 \mathbf{l}$ was prepared by catalytic hydrogenation of 1a (Scheme 7). $2 \mathrm{~m}$ was obtained by reaction of 1-bromooctane with uracil (Scheme 8).

\section{Enzyme assay}

The inhibition activity of new compounds against rat FAAH (rFAAH) and rat NAAA (rNAAA) was tested, using [3H]-AEA and d4-PEA, respectively, as substrates. The residual hydrolysis products of the substrates were determined by liquid chromatography-mass spectrometer (LC-MS).

\section{Results and discussion}

\subsection{SAR study}

It has been reported that carbamate and urea FAAH inhibitors interact with the nucleophilic Ser241 of FAAH through the electrophilic carbonyl group, and most of these inhibitors contain $O$-aryl or $N$-aryl moiety as leaving group. We speculated that the activity of uracil urea inhibitors may dependent on the presence of N1-carboxamide as the electrophilic carbonyl group and uracil as leaving group. Accordingly, two different chemical modifications were used to optimize the potency and selectivity of uracil urea derivatives. First, inspired by existed urea FAAH inhibitors, we replaced the uracil ring with chemical groups with different electronic properties to increase the leaving group ability of uracil. Second, we modified the side chain with phenyl-containing groups that can mimic the conformation and $\pi$-unsaturation of double bonds of anandamide, and provided better drug-like characteristics and the opportunity for structure exploration (Fig. 1).

In preliminary SAR study, analogues (1a-1e, Table 1) bearing a methyl were prepared to define positions available for substitution without adversely affecting the inhibitor potency. The results showed that substitutions of position N3 (1b), C6 (1d) and $\mathrm{N}^{\prime}$ (1e) of 1a resulted in a greatly diminished or complete loss in inhibition toward FAAH and NAAA, while substitution of position C5 (1c) slightly decreased the inhibition against both FAAH and NAAA. Therefore, we focused on the modification of C5 in the following studies.

Next, we did systematic substitution of $1 \mathbf{a}$ at C5 (1c, $2 \mathbf{a}-\mathbf{2 k})$ to investigate the effect of electronic properties of ring substitution on the inhibitory activity of uracil urea derivatives toward FAAH. Some analogues (2a, 2d, 2i, 2k) have been described by other groups were also synthesized and tested as control compounds. $^{36,37}$ The results suggested that the electronic properties of C5 substituents were of great significance for the inhibition towards both FAAH and NAAA (Table 2). Compared to parent inhibitor 1a, the electron-withdrawing substituents (2i-2k) exhibited 2-5 folds enhanced inhibition against FAAH.

Table 1 Inhibitory effects of compounds $1 a-1 e$ on rFAAH and rNAAA activities $^{a}$

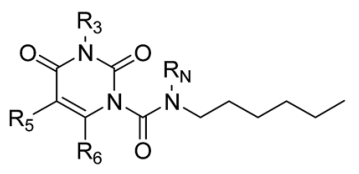

\begin{tabular}{lllllll}
\hline & $\mathrm{R}_{3}$ & $\mathrm{R}_{5}$ & $\mathrm{R}_{6}$ & $\mathrm{R}_{\mathrm{N}}$ & $\mathrm{IC}_{50}$ of FAAH $(\mathrm{nM})$ & $\mathrm{IC}_{50}$ of NAAA $(\mathrm{nM})$ \\
\hline $\mathbf{1 a}$ & $-\mathrm{H}$ & $-\mathrm{H}$ & $-\mathrm{H}$ & $-\mathrm{H}$ & $492 \pm 53$ & $990 \pm 170$ \\
$\mathbf{1 b}$ & $-\mathrm{Me}$ & $-\mathrm{H}$ & $-\mathrm{H}$ & $-\mathrm{H}$ & $7811 \pm 1563$ & $>10000$ \\
$\mathbf{1 c}$ & $-\mathrm{H}$ & $-\mathrm{Me}$ & $-\mathrm{H}$ & $-\mathrm{H}$ & $1026 \pm 205$ & $3650 \pm 840$ \\
$\mathbf{1 d}$ & $-\mathrm{H}$ & $-\mathrm{H}$ & $-\mathrm{Me}$ & $-\mathrm{H}$ & $>10000$ & $>10000$ \\
$\mathbf{1 e}$ & $-\mathrm{H}$ & $-\mathrm{H}$ & $-\mathrm{H}$ & $-\mathrm{Me}$ & $>10000$ & $>10000$
\end{tabular}

${ }^{a}$ Data are presented as $\mathrm{IC}_{50} \pm$ standard error of the mean. All experiments were performed in triplicate. 
Table 2 Inhibitory effects of compounds $1 a, 1 c, 2 a-2 m$ on rFAAH and rNAAA activities $^{a}$

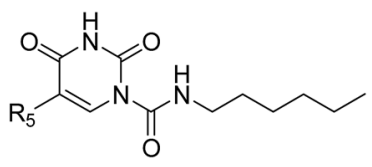

\begin{tabular}{|c|c|c|c|c|}
\hline & $\mathrm{R}_{5}$ & $\mathrm{IC}_{50}$ of FAAH $(\mathrm{nM})$ & $\mathrm{IC}_{50}$ of NAAA $(\mathrm{nM})$ & Selectivity \\
\hline $1 \mathbf{a}$ & $-\mathrm{H}$ & $492 \pm 53$ & $990 \pm 170$ & 2 \\
\hline $1 \mathrm{c}$ & $-\mathrm{Me}$ & $1026 \pm 205$ & $3650 \pm 840$ & 3.6 \\
\hline $2 a$ & $-\mathrm{Et}$ & $543 \pm 94$ & $1837 \pm 428$ & 3.4 \\
\hline $2 \mathbf{b}$ & $-\mathrm{OH}$ & $693 \pm 117$ & $5049 \pm 1103$ & 7.3 \\
\hline $2 c$ & $-\mathrm{CH}_{2} \mathrm{OH}$ & $425 \pm 75$ & $3265 \pm 519$ & 7.6 \\
\hline 2d & $-\mathrm{OEt}$ & $703 \pm 136$ & $1048 \pm 168$ & 1.5 \\
\hline $2 e$ & $-\mathrm{NH}_{2}$ & $1520 \pm 280$ & $5265 \pm 864$ & 3.5 \\
\hline $2 f$ & $-\mathrm{OAc}$ & $110 \pm 10$ & $190 \pm 20$ & 1.7 \\
\hline $2 \mathrm{~g}$ & $-\mathrm{CH}_{2} \mathrm{OAc}$ & $120 \pm 31$ & $271 \pm 25$ & 2.2 \\
\hline $2 \mathrm{~h}$ & -NHAc & $221 \pm 44$ & $423 \pm 78$ & 1.9 \\
\hline $2 \mathbf{i}$ & $-\mathrm{F}$ & $38 \pm 9$ & $250 \pm 50$ & 6.6 \\
\hline $2 \mathbf{j}$ & $-\mathrm{Ac}$ & $42 \pm 11$ & $486 \pm 89$ & 11.5 \\
\hline $2 \mathbf{k}$ & $-\mathrm{CN}$ & $25 \pm 5$ & $560 \pm 42$ & 22.4 \\
\hline URB597 & & $26 \pm 5$ & $>10000$ & \\
\hline
\end{tabular}

${ }^{a}$ Data are presented as $\mathrm{IC}_{50} \pm$ standard error of the mean. All experiments were performed in triplicate.

\begin{tabular}{lll}
\hline & IC $_{50}$ of & IC $_{50}$ of \\
Structure & FAAH $(n M)$ & NAAA (nM) \\
\hline
\end{tabular}

21

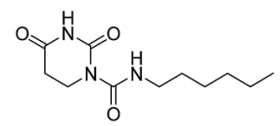

$>10000$

$>10000$

$2 \mathrm{~m}$

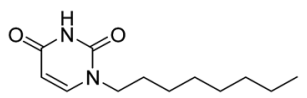

$>10000$

$>10000$
Among compounds $\mathbf{2 a - 2 k}, \mathbf{2} \mathbf{i}-\mathbf{2} \mathbf{k}$ were the three most potent inhibitors, being equipotent with URB597 tested under the same conditions. On the contrary, the electron-donating substituents (1c, 2a-2e) showed slightly decreased inhibitory activity against FAAH. We then tested whether further modulation of the electron-donating C5 substituents with electronwithdrawing group can restore the potency. The results showed that the addition of acetyl to the compounds $2 \mathbf{f}-\mathbf{2 h}$ resulted in a modest (3-7 folds) increase of inhibitory potency compared to corresponding derivatives $(\mathbf{2 b}, \mathbf{2 c}$ and $\mathbf{2 e})$. These results suggested that the electron-withdrawing C5 substitution was critical for potent FAAH inhibition. The reason might be such modulation increases the leaving group ability of uracil, and makes molecules more sensitive to nucleophilic attack of Ser241 of FAAH. To examine this hypothesis, two 1a derivative was synthesized and tested. Derivative $\mathbf{2 l}$ is the saturated derivative of $\mathbf{1 a}$ without the leaving group uracil. Derivative $\mathbf{2 m}$ without electrophilic carbonyl group was obtained by replacement of N1-carboxamide with methylene. The data showed that inhibitory activity of $\mathbf{2 l}$ and $\mathbf{2 m}$ against FAAH was completely eliminated. These results confirmed that uracil leaving group and N1-carboxamide group are critical for FAAH inhibition.
Except from enhancing inhibition potency towards FAAH, electron-withdrawing C5 substitution also increased the inhibition potency of uracil urea derivatives toward NAAA. For instance, acetyl substituents $\mathbf{2 f}-\mathbf{2 h}$ enhanced NAAA inhibition by 12-27 folds compared to the unsubstituted derivatives (2b, 2c and 2e). Electron-withdrawing C5 substituents exhibited weak selectivity towards FAAH over NAAA. The electron-withdrawing substituents failed to improve the selectivity towards FAAH over acid ceramidase. The $\mathrm{IC}_{50}$ values of electron-withdrawing substituents towards acid ceramidase (2i-2k) was an order of magnitude lower than $\mathbf{1 a}^{\mathbf{3 6}}$ These results suggested that electron-withdrawing substituents of uracil ring exhibited enhanced the inhibition potency, but their selectivity towards FAAH over acid ceramidase and NAAA was still not ideal. Further modification was required to enable high selectivity for FAAH over other competitive enzymes.

Finally, we further modified the side chain to improve the selectivity towards FAAH. FAAH hydrolyzes unsaturated substrates (e.g., anandamide) faster than saturated FAEs, while NAAA and acid ceramidase strongly prefer saturated substrates (e.g., PEA or ceramide). ${ }^{38}$ Replacement of the hexyl chain with an unsaturated group might mimic the $\pi$-characteristics and conformation of the anandamide, leading to binding affinity preference towards FAAH. Therefore, we optimized the chain terminus of $\mathrm{C} 5$ uracil substituents $(-\mathrm{H},-\mathrm{F},-\mathrm{OAc})$ with a phenyl ring, a chemical moiety that can mimic the conformation and $\pi$-unsaturation of the $\Delta^{8,9} / \Delta^{11,12}$ double bonds of anandamide. Three representative series where $\mathrm{R}_{5}=\mathrm{H}, \mathrm{F}$, OAc were designed and synthesized. As shown in Table 3, most of the analogous with an alkylphenyl group exhibited dramatically increased inhibitory potency against FAAH. The inhibitory potency was progressively improved by prolonging the linker length of the alkylphenyl. Interestingly, the inhibition activity of these substituents was independent of electron effect of C5 group, which was previously expected to significantly modulate the binding affinity of these derivatives. The results suggested that van der Waals interactions, strongly related to the closeness between inhibitors and protein surfaces, might be the most significant contribution to binding affinity.

These uracil urea derivatives exhibited different inhibition pattern against NAAA (Table 3). Most compounds with alkylphenyl replacement were less active than the parent hexyl derivatives. The optimal potency was observed with the linker length of $\mathrm{C} 5$ (for 5-F series) or $\mathrm{C} 4$ (for 5-H and 5-OAc series) methylene spacer, and the inhibition potency progressively decreased with lengthened or shortened linker. The tight binding pocket of NAAA, may explain the loss of NAAA inhibitory and gain in FAAH selectivity by bulkier structures. Most of the alkylphenyl derivatives were more selective for FAAH compared to parent inhibitors (1a, 2f and 2i). Among these alkylphenyl derivatives $\mathbf{3 g}$, $\mathbf{3 t}$ and $\mathbf{3 u}$ were the most promising inhibitors with high potency and selectivity towards FAAH. We further substituted the phenylalkyl chain of $\mathbf{3 t}$ and $3 \mathbf{u}$ with biphenyl group and tested whether biphenyl modification will further enhance the potency. As showed in Table 4, the biphenyl derivatives (4a, 4c and 4d) were 3-16 folds more potent or similar potent (4b) compared to the parent inhibitors (3t and 
Table 3 Inhibitory effects of compounds $3 a-3 u$ on rFAAH and rNAAA activities $^{a}$

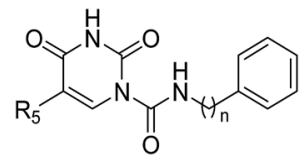

\begin{tabular}{lccccl}
\hline & $\mathrm{R}_{5}$ & $n$ & IC $_{50}$ of FAAH $(\mathrm{nM})$ & $\mathrm{IC}_{50}$ of NAAA $(\mathrm{nM})$ & Selectivity \\
\hline 3a & $-\mathrm{H}$ & 1 & $155 \pm 23$ & $8020 \pm 1290$ & 52 \\
3b & & 2 & $333 \pm 105$ & $6340 \pm 1080$ & 19 \\
3c & 3 & $19 \pm 7$ & $1572 \pm 326$ & 83 \\
3d & & 4 & $13 \pm 4$ & $305 \pm 57$ & 23 \\
3e & 5 & $11 \pm 1$ & $435 \pm 63$ & 40 \\
3f & 6 & $4 \pm 0.9$ & $2490 \pm 372$ & 623 \\
3g & 7 & $3 \pm 0.8$ & $4768 \pm 541$ & 1589 \\
3h & $-\mathrm{F}$ & 1 & $122 \pm 10$ & $4655 \pm 482$ & 38 \\
3i & 2 & $98 \pm 12$ & $4510 \pm 371$ & 9.4 \\
3j & 3 & $21 \pm 3$ & $440 \pm 96$ & 20 \\
3k & 4 & $16 \pm 2$ & $481 \pm 35$ & 30 \\
31 & 5 & $13 \pm 3$ & $105 \pm 11$ & 8 \\
3m & 6 & $4 \pm 1$ & $290 \pm 30$ & 73 \\
3n & 7 & $3 \pm 0.8$ & $822 \pm 85$ & 274 \\
3o & - OAc & 1 & $51 \pm 10$ & $5880 \pm 647$ & 115 \\
3p & 2 & $96 \pm 12$ & $5440 \pm 1023$ & 57 \\
3q & 3 & $32 \pm 6$ & $810 \pm 100$ & 25 \\
3r & 4 & $18 \pm 3$ & $220 \pm 25$ & 12 \\
3s & 5 & $10 \pm 1$ & $3545 \pm 641$ & 355 \\
3t & 6 & $5 \pm 1.1$ & $7908 \pm 855$ & 1648 \\
3u & 7 & $3 \pm 0.4$ & $9382 \pm 1425$ & 3127 \\
& & & &
\end{tabular}

${ }^{a}$ Data are presented as $\mathrm{IC}_{50} \pm$ standard error of the mean. All experiments were performed in triplicate.

Table 4 Inhibitory effects of compounds $4 a-4 d$ on rFAAH and rNAAA activities $^{a}$

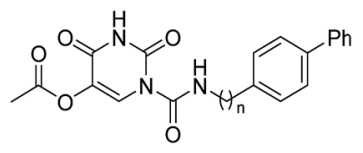

\begin{tabular}{llll}
\hline & $n$ & $\mathrm{IC}_{50}$ of FAAH $(\mathrm{nM})$ & $\mathrm{IC}_{50}$ of NAAA $(\mathrm{nM})$ \\
\hline 4a & 1 & $1.1 \pm 0.2$ & $>10000$ \\
4b & 2 & $8.3 \pm 1.2$ & $>10000$ \\
4c & 3 & $0.3 \pm 0.05$ & $>10000$ \\
4d & 4 & $0.8 \pm 0.1$ & $>10000$
\end{tabular}

${ }^{a}$ Data are presented as $\mathrm{IC}_{50} \pm$ standard error of the mean. All experiments were performed in triplicate.

3u). Moreover, the selectivity of biphenyl substituents towards FAAH was significantly enhanced. 4a-4d exhibited profound selectivity ( $>3000$ folds) towards FAAH over NAAA.

\subsection{Selectivity evaluation}

NAAA, acid ceramidase (AC) and endocannabinoid hydrolase monoacylglycerol lipase (MAGL) are three competitive targets for the uracil urea derivatives. Representative inhibitors (2f, $2 \mathbf{i}$, $3 \mathbf{u}$ and $\mathbf{4 c}$ ) were selected and their selectivity towards FAAH was examined. As shown in Table 5, the inhibitors were highly selective for FAAH over MAGL. Hexyl derivatives $2 f$ and $2 \mathbf{i}$ exhibited inhibitory effects against all the three enzymes. Phenyl ring substitutions at the terminus of the hexyl side chain enhanced the binding affinity of the inhibitors to FAAH over NAAA (2f, 1.7 folds; $2 \mathbf{i}, 6.5$ folds; $3 \mathbf{u}$ and $4 \mathbf{c},>3000$ folds), but it did not decrease their inhibition potency towards AC. Notably, biphenyl group substitution dramatically increased both potency and selectivity of the derivatives towards FAAH. The most potent inhibitor $\mathbf{4 c}$ was more than 3000 folds selective for FAAH over NAAA, and modestly selective for FAAH over AC (Table 5).

The potency and selectivity of inhibitors were depended on the compound reactivity as well as the molecular shape and flexibility. The inhibition profile of uracil urea derivatives was modulated by electron properties of the C5 substituents and the conformation of the side chain. Electron-withdrawing substituent enhances both potency and selectivity for FAAH over NAAA, but failed to improve the selectivity towards FAAH over AC. ${ }^{36}$ Electron-withdrawing substitution turning 1a to a dual inhibitor of FAAH-AC. On the other hand, the side chain is the major factor contributing to the selectivity of uracil urea derivatives. Incorporation of phenyl-containing group into the side chain significantly enhanced their inhibition potency and selectivity towards FAAH over NAAA and AC, turning the uracil urea scaffold from a multi-target inhibitor to a FAAH-selective inhibitor.

\subsection{Investigations of the inhibition mechanism}

To explore the pharmacological properties of uracil urea derivatives, we analysed their interaction pattern with FAAH. Representative inhibitor 4c was selected in these studies. As well as its significant inhibition towards recombinant rat FAAH protein $\left(\mathrm{IC}_{50}=0.3 \pm 0.05 \mathrm{nM}\right.$, Table 4$), 4 \mathrm{c}$ displayed a profound inhibition toward recombinant human FAAH $\left(\mathrm{IC}_{50}=0.6 \pm 0.1\right.$ nM) (Fig. 2A). Kinetic analysis revealed that $4 \mathrm{c}$ rapidly inhibited rFAAH $\left(t_{1 / 2}<1\right.$ minute) (Fig. 2B), and changed the maximal catalytic velocity $\left(V_{\max }\right)$ of rFAAH $\left(V_{\max }\right.$ in pmol per min per $\mathrm{mg}$ protein, vehicle: $2056 \pm 107$; and 4c, $50 \mathrm{nM}$ : $698 \pm 84)$, but it did not affect Michaelis-Menten constant $K_{\mathrm{m}}\left(K_{\mathrm{m}}\right.$ in $\mu \mathrm{M}$, vehicle: 9.8 \pm 0.3 ; and 4c, $50 \mathrm{nM}$ : $10.4 \pm 0.6$ ) (Fig. 2C). No recovery of the rFAAH activity was observed by dialysis of the 4c-rFAAH

Table 5 Selectivity screening of compounds $2 \mathrm{f}, 2 \mathrm{i}, 3 \mathrm{u}$ and $4 \mathrm{c}^{a}$

\begin{tabular}{lllll}
\hline & $\begin{array}{l}\mathrm{IC}_{50} \text { of rFAAH } \\
(\mathrm{nM})\end{array}$ & $\begin{array}{l}\mathrm{IC}_{50} \text { of rNAAA } \\
(\mathrm{nM})\end{array}$ & $\begin{array}{l}\mathrm{IC}_{50} \text { of } \mathrm{rAC} \\
(\mathrm{nM})\end{array}$ & $\begin{array}{l}\mathrm{IC}_{50} \text { of } \\
\text { rMAGL }(\mathrm{nM})\end{array}$ \\
\hline $\mathbf{2 f}$ & $110 \pm 10$ & $190 \pm 20$ & $102 \pm 23$ & $>10000$ \\
$\mathbf{2 i}$ & $38 \pm 9$ & $250 \pm 50$ & $45 \pm 9$ & $>10000$ \\
$3 \mathbf{3 u}$ & $3 \pm 0.4$ & $9382 \pm 1425$ & $68 \pm 10$ & $>10000$ \\
$\mathbf{4 c}$ & $0.3 \pm 0.05$ & $>10000$ & $360 \pm 74$ & $>10000$
\end{tabular}

${ }^{a}$ Data are presented as $\mathrm{IC}_{50} \pm$ standard error of the mean. All experiments were performed in triplicate. 

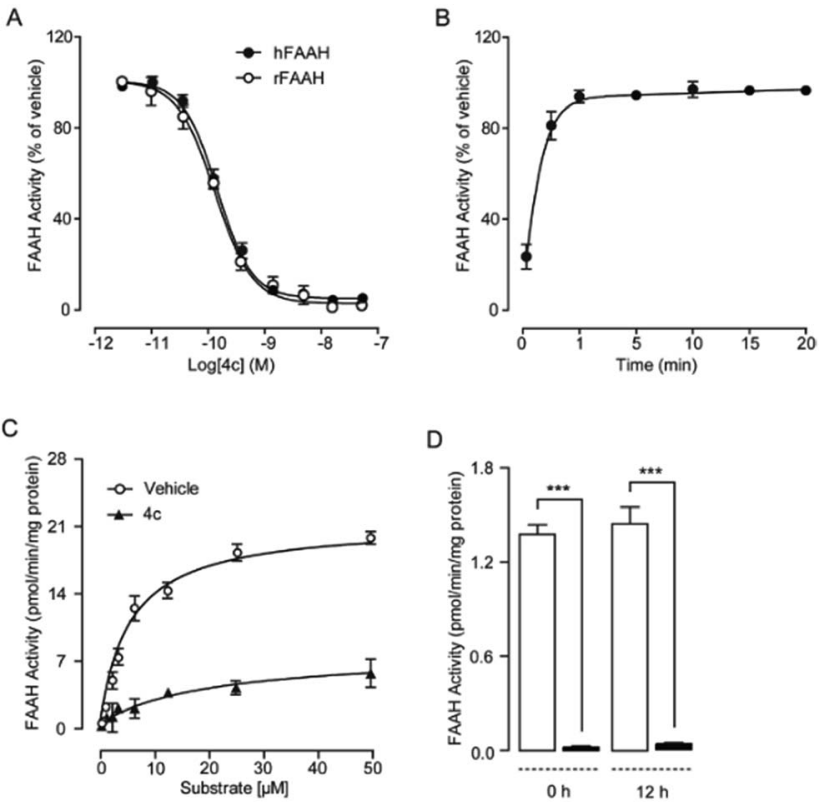

Fig. 2 Effect of 4c on FAAH activity in vitro. (A) Dose-dependent inhibition of recombinant rat FAAH (rFAAH) and recombinant human FAAH (hFAAH) activity by $4 \mathrm{c}$. (B) Time course of rFAAH inhibition by $4 \mathrm{c}$ $(50 \mathrm{nM})$. (C) Michaelis-Menten analysis of the FAAH reaction in the presence of vehicle (open circles, $1 \%$ DMSO) or 4c (closed triangles, 50 $n M)$. (D) FAAH activity in the presence of vehicle (open bars $1 \%$ DMSO) or $4 \mathrm{c}$ (closed bars, $50 \mathrm{nM}$ ) before dialysis and 12 hours after dialysis. Results are expressed as mean $\pm \operatorname{SEM}(n=4-6)$. $* * * P<0.001$

interaction complex even after 12 hours (Fig. 2C). These results indicated that $\mathbf{4 c}$ was an irreversible and non-competitive FAAH inhibitor, thereby providing strong evidence for the formation of covalent bonds between compound and enzyme.

\subsection{Biological stability evaluation}

The hydrolysis of compounds (2f, $2 \mathbf{i}$ and $4 \mathbf{c}$ ) was studied in $80 \%$ $(\mathrm{v} / \mathrm{v})$ rat plasma at $37^{\circ} \mathrm{C}$. The results showed that more than $60 \%$ of compounds were hydrolyzed after $10 \mathrm{~min}$ incubation (Table 6). Analogues $2 \mathbf{f}$ and $\mathbf{2 i}$ containing less sterically hindered hexyl chain were cleaved more rapidly than the bulkier compound 4c. LC-MS analysis of degradation products of inhibitors (2f, $2 \mathbf{i}$ and $\mathbf{4 c}$ ) showed the formation of hexylamine and 4-biphenylpropylamine, which resulted from the hydrolysis of the N1-carboxamide (data not shown). FAAH is broadly

Table 6 Percent of compounds $2 \mathrm{f}, 2 \mathrm{i}$ and $4 \mathrm{c}$ remaining after incubation in $80 \%(\mathrm{v} / \mathrm{v})$ rat plasma ${ }^{a}$

\begin{tabular}{lllll}
\hline & & 2f & $\mathbf{2 i}$ & $\mathbf{4 c}$ \\
\hline \multirow{2}{*}{ Remain inhibitors } & $0 \mathrm{~min}$ & $100 \%$ & $100 \%$ & $100 \%$ \\
& $5 \mathrm{~min}$ & $15 \%$ & $21 \%$ & $56 \%$ \\
& $10 \mathrm{~min}$ & $7 \%$ & $11 \%$ & $33 \%$ \\
& $15 \mathrm{~min}$ & n.a. & n.a. & $8 \%$
\end{tabular}

${ }^{a}$ Compounds were measured at $10 \mu \mathrm{M}$ in $80 \%(\mathrm{v} / \mathrm{v})$ rat plasma with $2.5 \%$ DMSO. distributed throughout the body, involved in a complex anandamide-based signalling system. Most of current FAAH inhibitors, e.g. PF-04457845, are distributed throughout all tissues and organs after administration. They are suitable for the systemic application, but probably not optimal agents to investigate the function of FAAH in specific organ or tissue. The inhibitors we developed exert acute FAAH inhibitory in the target site and rapidly inactivated to prevent unwanted systemic effects. Our findings may offer a new topically applied tool to investigate the function of FAAH at a selected tissue or organ.

\section{Conclusions}

Here, we report the synthesis and characterization of a series of uracil urea derivatives, designed as FAAH inhibitors by progressive modification of 1a. SAR studies suggested that electron-withdrawing substituents in the C5 position enhanced the potency of FAAH inhibition and the replacement of the side chain with phenylalkyl moieties or biphenyl groups significantly improved both the inhibitory potency and selectivity towards FAAH. The two most potent inhibitors, $4 \mathbf{c}\left(\mathrm{IC}_{50}=0.3 \pm\right.$ $0.05 \mathrm{nM})$ and $4 \mathrm{~d}\left(\mathrm{IC}_{50}=0.8 \pm 0.1 \mathrm{nM}\right)$ showed moderate to high selectivity towards FAAH over other endocannabinoidmetabolizing enzymes. Rapid dilution and kinetic analysis indicate that $\mathbf{4 c}$ is a selective, irreversible and non-competitive FAAH inhibitor. This study provides us some promising FAAH inhibitors and an optimized scaffold for the development of strategies to investigate tropical FAAH function, and to explore new therapeutics for inflammation, cancer, and neuropathic diseases.

\section{Acknowledgements}

We thank Dr Daniele Piomelli at the University of California, Irvine for the kind gifts of the HEK293-rNAAA cells and the HEK293-rFAAH cells. This study was supported by grants from National Natural Sciences Foundation of China (No. 81373273 to QY, No. 81602974 to YL), Key Research Program of Frontier Science, CAS, Grant No. QYZDJ-SSW-SLH033, The Major State Basic Research Development Program of China (grant number 2014CB965101), and China Postdoctoral Science Foundation Funded Project (2016M592876XB) to YL.

\section{References}

1 D. K. Giang and B. F. Cravatt, Proc. Natl. Acad. Sci. U. S. A., 1997, 94, 2238.

2 S. Shin, T. H. Lee, N. C. Ha, H. M. Koo, S. Y. Kim, H. S. Lee, Y. S. Kim and B. H. Oh, EMBO J., 2002, 21, 2509.

3 M. H. Bracey, M. A. Hanson, K. R. Masuda, R. C. Stevens and B. F. Cravatt, Science, 2002, 298, 1793.

4 A. H. Lichtman, D. Leung, C. C. Shelton, A. Saghatelian, C. Hardouin, D. L. Boger and B. F. Cravatt, J. Pharmacol. Exp. Ther., 2004, 311, 441.

5 S. Kathuria, S. Gaetani, D. Fegley, F. Valino, A. Duranti, A. Tontini, M. Mor, G. Tarzia, G. La Rana, A. Calignano, 
A. Giustino, M. Tattoli, M. Palmery, V. Cuomo and D. Piomelli, Nat. Med., 2003, 9, 76.

6 B. F. Cravatt, K. Demarest, M. P. Patricelli, M. H. Bracey, D. K. Giang, B. R. Martin and A. H. Lichtman, Proc. Natl. Acad. Sci. U. S. A., 2001, 98, 9371.

7 C. J. Fowler, K. O. Jonsson and G. Tiger, Biochem. Pharmacol., 2001, 62, 517.

8 H. S. Hansen, B. Moesgaard, H. H. Hansen and G. Petersen, Chem. Phys. Lipids, 2000, 108, 135.

9 H. S. Hansen, Exp. Neurol., 2010, 224, 48.

10 H. H. Schmid, P. C. Schmid and V. Natarajan, Prog. Lipid Res., 1990, 29, 1.

11 J. M. Walker, S. M. Huang, N. M. Strangman, K. Tsou and M. C. Sanudo-Pena, Proc. Natl. Acad. Sci. U. S. A., 1999, 96, 12198.

12 M. Salaga, M. Sobczak and J. Fichna, Eur. J. Pharm. Sci., 2014, 52, 173.

13 K. Otrubova, C. Ezzili and D. L. Boger, Bioorg. Med. Chem. Lett., 2011, 21, 4674.

14 M. Seierstad and J. G. Breitenbucher, J. Med. Chem., 2008, 51, 7327.

15 D. L. Boger, H. Miyauchi, W. Du, C. Hardouin, R. A. Fecik, H. Cheng, I. Hwang, M. P. Hedrick, D. Leung, O. Acevedo, C. R. Guimaraes, W. L. Jorgensen and B. F. Cravatt, J. Med. Chem., 2005, 48, 1849.

16 L. Chang, L. Luo, J. A. Palmer, S. Sutton, S. J. Wilson, A. J. Barbier, J. G. Breitenbucher, S. R. Chaplan and M. Webb, Br. J. Pharmacol., 2006, 148, 102.

17 G. Tarzia, A. Duranti, A. Tontini, G. Piersanti, M. Mor, S. Rivara, P. V. Plazzi, C. Park, S. Kathuria and D. Piomelli, J. Med. Chem., 2003, 46, 2352.

18 G. Moreno-Sanz, A. Duranti, L. Melzig, C. Fiorelli, G. F. Ruda, G. Colombano, P. Mestichelli, S. Sanchini, A. Tontini, M. Mor, T. Bandiera, R. Scarpelli, G. Tarzia and D. Piomelli, J. Med. Chem., 2013, 56, 5917.

19 M. Mor, S. Rivara, A. Lodola, P. V. Plazzi, G. Tarzia, A. Duranti, A. Tontini, G. Piersanti, S. Kathuria and D. Piomelli, J. Med. Chem., 2004, 47, 4998.

20 M. Mor, A. Lodola, S. Rivara, F. Vacondio, A. Duranti, A. Tontini, S. Sanchini, G. Piersanti, J. R. Clapper, A. R. King, G. Tarzia and D. Piomelli, J. Med. Chem., 2008, 51, 3487.

21 K. Ahn, S. E. Smith, M. B. Liimatta, D. Beidler, N. Sadagopan, D. T. Dudley, T. Young, P. Wren, Y. Zhang, S. Swaney, K. Van Becelaere, J. L. Blankman, D. K. Nomura, S. N. Bhattachar, C. Stiff, T. K. Nomanbhoy, E. Weerapana, D. S. Johnson and B. F. Cravatt, J. Pharmacol. Exp. Ther., 2011, 338, 114.
22 M. Kono, T. Matsumoto, T. Kawamura, A. Nishimura, Y. Kiyota, H. Oki, J. Miyazaki, S. Igaki, C. A. Behnke, M. Shimojo and M. Kori, Bioorg. Med. Chem., 2013, 21, 28.

23 G. L. Li, H. Winter, R. Arends, G. W. Jay, V. Le, T. Young and J. P. Huggins, Br. J. Clin. Pharmacol., 2012, 73, 706.

24 J. M. Keith, R. Apodaca, M. Tichenor, W. Xiao, W. Jones, J. Pierce, M. Seierstad, J. Palmer, M. Webb, M. Karbarz, B. Scott, S. Wilson, L. Luo, M. Wennerholm, L. Chang, S. Brown, M. Rizzolio, R. Rynberg, S. Chaplan and J. G. Breitenbucher, ACS Med. Chem. Lett., 2012, 3, 823.

25 D. S. Johnson, C. Stiff, S. E. Lazerwith, S. R. Kesten, L. K. Fay, M. Morris, D. Beidler, M. B. Liimatta, S. E. Smith, D. T. Dudley, N. Sadagopan, S. N. Bhattachar, S. J. Kesten, T. K. Nomanbhoy, B. F. Cravatt and K. Ahn, ACS Med. Chem. Lett., 2011, 2, 91.

26 S. O. Alapafuja, S. P. Nikas, I. T. Bharathan, V. G. Shukla, M. L. Nasr, A. L. Bowman, N. Zvonok, J. Li, X. Shi, J. R. Engen and A. Makriyannis, J. Med. Chem., 2012, 55, 10074.

27 A. Lodola, M. Mor, S. Rivara, C. Christov, G. Tarzia, D. Piomelli and A. J. Mulholland, Chem. Commun., 2008, 214. 28 C. J. Fowler, Eur. Neuropsychopharmacol., 2015, 25, 749.

29 X. Wang, K. Sarris, K. Kage, D. Zhang, S. P. Brown, T. Kolasa, C. Surowy, O. F. El Kouhen, S. W. Muchmore, J. D. Brioni and A. O. Stewart, J. Med. Chem., 2009, 52, 170.

30 M. Feledziak, C. Michaux, A. Urbach, G. Labar, G. G. Muccioli, D. M. Lambert and J. Marchand-Brynaert, J. Med. Chem., 2009, 52, 7054.

31 G. G. Muccioli, N. Fazio, G. K. Scriba, W. Poppitz, F. Cannata, J. H. Poupaert, J. Wouters and D. M. Lambert, J. Med. Chem., 2006, 49, 417.

32 G. Palermo, A. D. Favia, M. Convertino and M. De Vivo, ChemMedChem, 2016, 11, 1252.

33 A. D. Favia, D. Habrant, R. Scarpelli, M. Migliore, C. Albani, S. M. Bertozzi, M. Dionisi, G. Tarozzo, D. Piomelli, A. Cavalli and M. De Vivo, J. Med. Chem., 2012, 55, 8807.

34 L. Bertolacci, E. Romeo, M. Veronesi, P. Magotti, C. Albani, M. Dionisi, C. Lambruschini, R. Scarpelli, A. Cavalli, M. De Vivo, D. Piomelli and G. Garau, J. Am. Chem. Soc., 2013, 135, 22.

35 Y. Qiu, Y. Zhang, Y. Li and J. Ren, Molecules, 2016, 21, 229. 36 D. Pizzirani, C. Pagliuca, N. Realini, D. Branduardi, G. Bottegoni, M. Mor, F. Bertozzi, R. Scarpelli, D. Piomelli and T. Bandiera, J. Med. Chem., 2013, 56, 3518.

37 N. Realini, C. Solorzano, C. Pagliuca, D. Pizzirani, A. Armirotti, R. Luciani, M. P. Costi, T. Bandiera and D. Piomelli, Sci. Rep., 2013, 3, 1035.

38 N. Ueda, K. Yamanaka and S. Yamamoto, J. Biol. Chem., 2001, 276, 35552. 